\title{
A Specific Probe Substrate for Evaluation of CYP4A11 Activity in Human Tissue Microsomes and a Highly Selective CYP4A11 Inhibitor: Luciferin-4A and Epalrestat ${ }^{\mathbb{S}}$
}

\author{
Satoshi Yamaori, Noriyuki Araki, Mio Shionoiri, Kurumi Ikehata, Shinobu Kamijo, \\ Shigeru Ohmori, and Kazuhito Watanabe ${ }^{1}$ \\ Department of Pharmacy, Shinshu University Hospital, Matsumoto, Japan (S.Y., S.O.); Department of Biochemical Pharmacology \\ and Toxicology, Graduate School of Medicine, Shinshu University, Matsumoto, Japan (S.Y., S.K., S.O.); and Department of \\ Hygienic Chemistry, Faculty of Pharmaceutical Sciences, Hokuriku University, Kanazawa, Japan (N.A., M.S., K.I., K.W.)
}

Received March 30, 2018; accepted June 29, 2018

\begin{abstract}
The specificity of cytochrome P450 4A11 (CYP4A11) against luciferin-4A $O$-demethylation in human liver microsomes (HLMs) and human renal microsomes (HRMs) and selectivity of CYP4A11 inhibition by epalrestat were investigated. Kinetic analysis of luciferin-4A O-demethylation yielded $V_{\max }$ and $S_{50}$ values of $39.7 \mathrm{pmol} / \mathrm{min}$ per milligram protein and $43.2 \mu \mathrm{M}$ for HLMs (Hill coefficient 1.24) and $39.4 \mathrm{pmol} / \mathrm{min}$ per milligram protein and $33.8 \mu \mathrm{M}$ for HRMs (Hill coefficient 1.34), respectively. Among the selective CYP inhibitors tested, HET0016 (CYP4 inhibitor) exclusively inhibited luciferin-4A O-demethylation by HLMs and HRMs. Furthermore, anti-CYP4A11 antibody nearly abolished the activity of both tissue microsomes. Luciferin-4A $\mathrm{O}$-demethylase activity of HLMs was significantly correlated with lauric acid $\omega$-hydroxylase activity, a marker of CYP4A11 activity $(r=0.904, P<0.0001)$. Next, effects of

epalrestat on CYP-mediated drug oxidations were examined. Epalrestat showed the most potent inhibition against CYP4A11 $\left(\mathrm{IC}_{50}=1.82 \mu \mathrm{M}\right)$ among the 17 recombinant enzymes tested. The inhibitory effect of epalrestat on CYP4A11 was at least 10-fold stronger than those on CYP4F2, CYP4F3B, and CYP4F12. For known CYP4 inhibitors, in contrast, HET0016 inhibited the activities of CYP4A11 and CYP4F2 $\left(\mathrm{IC}_{50}=0.0137-0.0182 \mu \mathrm{M}\right) ; 17$-octadecynoic acid reduced activities of CYP4A11, CYP4F2, CYP4F3B, and CYP4F12 to a similar extent $\left(\mathrm{IC}_{50}=5.70-17.7 \mu \mathrm{M}\right)$. Epalrestat selectively and effectively inhibited the CYP4A11 activity of HLMs $\left(\mathrm{IC}_{50}=0.913 \mu \mathrm{M}\right)$ and HRMs $\left(\mathrm{IC}_{50}=0.659 \mu \mathrm{M}\right)$. These results indicated that luciferin-4A $O$-demethylase activity is a good CYP4A11 marker of HLMs and HRMs, and that epalrestat is a more selective CYP4A11 inhibitor compared with known CYP4 inhibitors.
\end{abstract}

\section{Introduction}

Cytochrome P450 (CYP, P450) is a heme-containing enzyme that oxidizes a wide variety of endogenous and exogenous compounds, including steroids, fatty acids, vitamins, drugs, and xenobiotic chemicals (Nelson et al., 1996). The CYP4 family of enzymes in humans consists of six subfamilies, CYP4A, CYP4B, CYP4F, CYP4V, CYP4X, and CYP4Z, which typically $\omega$-hydroxylate endogenous fatty acids and eicosanoids (Edson and Rettie, 2013). Among these enzymes, CYP4A11 is important for catalyzing $\omega$-hydroxylation of lauric acid and arachidonic acid in the human liver and kidneys (Powell et al., 1996, 1998; Amet et al., 1997; Lasker et al., 2000). In

This work was supported in part by a Grant-in-Aid for Young Scientists (B) [Grant 23790159] from the Ministry of Education, Culture, Sports, Science, and Technology of Japan.

${ }^{1}$ Current affiliation: Center for Supporting Pharmaceutical Education, Daiichi University of Pharmacy, Fukuoka, Japan.

https://doi.org/10.1124/jpet.118.249557.

S This article has supplemental material available at jpet.aspetjournals.org. particular, an $\omega$-hydroxylated metabolite of arachidonic acid produced by renal CYP4A11, 20-hydroxyeicosatetraenoic acid, plays essential roles in the regulation of blood pressure and sodium reabsorption (Wu et al., 2014). Several genetic polymorphisms have appeared in the CYP4A11 allele nomenclature (https://www.pharmvar.org/gene/CYP4A11). In previous in vitro studies, many of these variants have been shown to cause reduced arachidonic acid $\omega$-hydroxylase activity (Gainer et al., 2005; Saito et al., 2015). Certain CYP4A11 genetic polymorphisms have been suggested to be associated with hypertension and coronary artery diseases (Gainer et al., 2005; Sugimoto et al., 2008; Hermann et al., 2009). Thus, functional analysis of CYP4A11 is very important to clarify its physiologic roles.

Lauric acid has been widely used as a probe substrate of CYP4A11, because this enzyme exhibits high oxidative activity toward lauric acid (Hoch et al., 2000; Choi et al., 2018). However, the measurement of lauric acid $\omega$-hydroxylation requires a radiolabeled substrate, complicated procedures, such as derivatization of its $\omega$-hydroxylated metabolites, 
and/or high-precision instruments, such as gas chromatog$\mathrm{raph} / \mathrm{mass}$ spectrometer and liquid chromatograph/mass spectrometer (Dirven et al., 1991; Chaurasia et al., 1995; Crespi et al., 2006; Choi et al., 2018), although these instruments are suitable for comprehensive analysis of endogenous and exogenous compounds in biologic samples. In contrast, luminogenic assays are simple and rapid methods (Cali et al., 2006). Among the 21 recombinant human CYP enzymes examined, CYP4A11 has the most prominent $O$-demethylase activity of luciferin-4A [2-(6-methoxyquinolin-2-yl)-4,5-dihydrothiazole4-carboxylic acid; Fig. 1A], although CYP1A2, CYP2C8, and CYP2C9 show only modest activity (https:/www.promega.jp/ resources/pubhub/enotes/selective-cytochrome-p450-4a11enzyme-assay-using-a-novel-bioluminescent-probe-substrate/). There has been only one study using luciferin-4A as a substrate, in which catalytic activities of CYP4A11 variants were measured with genetically engineered Escherichia coli cells and purified proteins (Choi et al., 2013). However, the CYP-isoform specificity of luciferin-4A $O$-demethylase activity in microsomes from tissues, such as human liver and kidney, remains to be elucidated. Therefore, it is necessary to verify whether luciferin-4A is a good probe substrate for human tissue microsomal CYP4A11.

In addition to the metabolism of endogenous compounds, CYP4A11 is involved in the metabolism of some marketed drugs such as febuxostat (Mukoyoshi et al., 2008), exemestane (Kamdem et al., 2011), tofogliflozin (Yamane et al., 2015), and epalrestat (Interview Form "KINEDAC Tablets 50 mg" sixth edition, 2013; Fig. 1B). To clarify the involvement of a certain CYP isoform in drug metabolism, selective chemical inhibitors and antibodies are applied for inhibition studies. The 17-octadecynoic acid (17-ODYA; Fig. 1C) and HET0016 (Fig. 1D) are known to be chemical inhibitors of CYP4A11 (Lasker et al., 2000; Kehl et al., 2002). However, these inhibitors are not selective for CYP4A11. The 17-ODYA was first characterized as a suicidal inhibitor of leukotriene $\mathrm{B}_{4} \omega$-hydroxylase, including CYP4F enzymes (Shak et al., 1985). Later, 17-ODYA was found to inhibit not only the $\omega$-hydroxylation of lauric acid and arachidonic acid but also arachidonic acid epoxidation (Muerhoff et al., 1989; Zou et al., 1994; Jarrar et al., 2013). Furthermore, this compound has been shown to inhibit arachidonic acid $\omega$-hydroxylase activity of purified CYP4F2 and DB289 [2,5-bis(4-amidinophenyl)furan-bis- $O$-methylamidoxime]
O-demethylase activity of recombinant CYP4F2 and CYP4F3B (Lasker et al., 2000; Wang et al., 2006). In contrast, HET0016 was developed as a selective inhibitor of arachidonic acid $\omega$-hydroxylase (Miyata et al., 2001). It has been reported that HET0016 inhibits arachidonic acid $\omega$-hydroxylase activity of recombinant CYP4F2 and CYP4F3B (Kehl et al., 2002). A more recent study showed that this compound potently inhibits CYP2B6-catalyzed bupropion hydroxylation in human liver microsomes (HLMs) (Choi et al., 2018). Thus, a more selective inhibitor of CYP4A11 is essential to elucidate its roles in drug metabolism as well as physiologic function.

In this study, we examined the specificity of CYP4A11 against luciferin-4A $O$-demethylation in HLMs and human renal microsomes (HRMs) and its selectivity against epalrestatmediated inhibition. In this work, we report that luciferin-4A $O$-demethylase activity is a good CYP4A11 marker of HLMs and HRMs. Furthermore, our study indicated that CYP4A11 inhibition by epalrestat was more selective than that by known CYP4 inhibitors.

\section{Materials and Methods}

Materials. $N$-Desmethyl diltiazem was a gift from Tanabe Seiyaku (Osaka, Japan). Microsomes from baculovirus-infected insect cells expressing CYP (CYP1A1, CYP1A2, CYP1B1, CYP2A6, CYP2B6, CYP2C8, CYP2C9.1, CYP2C19, CYP2D6, and CYP4A11) each with NADPH-CYP reductase (supersomes), microsomes from baculovirusinfected insect cells expressing CYP (CYP2E1, CYP2J2, CYP3A4, CYP3A5, CYP4F2, CYP4F3B, and CYP4F12) each with NADPH-CYP reductase and cytochrome $b_{5}$ (supersomes), pooled HLMs (50-donor pool, mixed gender, catalog 452156), dibenzylfluorescein, and 7-hydroxywarfarin were purchased from BD Biosciences (Woburn, MA). Sixteen HLMs for the Reaction Phenotyping Kit Version 6 and pooled HRMs (8-donor pool, mixed gender, catalogue H0610.R) were obtained from XenoTech (Lenexa, KS). Luciferin-2J2/4F12, luciferin$4 \mathrm{~A}$, luciferin-4F2/3, luciferin-4F12, luciferin detection reagent (LDR), LDR with esterase, and beetle luciferin were purchased from Promega (Madison, WI). Other chemicals were obtained from the following sources: 7-ethoxyresorufin, 7-benzoxyresorufin, resorufin, fluorescein, tranylcypromine, thio-TEPA, trimethoprim, sulfaphenazole, and diethyldithiocarbamate from Sigma-Aldrich (St. Louis, MO); $\alpha$-naphthoflavone from Tokyo Chemical Industry (Tokyo, Japan); 3-O-methylfluorescein and (-)- $N$-3-benzyl-phenobarbital from Cypex (Dundee, UK); $S$-warfarin, 4-hydroxymephenytoin, HET-0016, and 17-ODYA from Cayman Chemical (Ann Arbor, MI); coumarin,
A<smiles>COc1ccc2nc(C3=NC(C(=O)O)CS3)ccc2c1</smiles>

Luciferin-4A

C<smiles>C#CCCCCCCCCCCCCCCCC(=O)O</smiles>

17-ODYA
B<smiles>CC(/C=C1\SC(=S)N(CC(=O)O)C1=O)=C\c1ccccc1</smiles>

Epalrestat

D<smiles>CCCCc1ccc(N/C=N/O)c(C)c1</smiles>

Fig. 1. Chemical structures of luciferin-4A, epalrestat, 17-ODYA, and HET0016. Chemical structures of luciferin-4A (A), epalrestat (B), 17-ODYA (C), and HET0016 (D). 
TABLE 1

Experimental conditions for enzyme assays

\begin{tabular}{|c|c|c|c|c|}
\hline Enzymes & Concentrations & Substrates & Concentrations & Incubation Time \\
\hline & (mg protein/ml) & & $(\mu \mathrm{M})$ & $(\min )$ \\
\hline HLMs & 0.05 & 7-Ethoxyresorufin & 0.5 & 15 \\
\hline HLMs & 0.1 & $S$-Warfarin & 6 & 20 \\
\hline HLMs & 0.5 & $S$-Mephenytoin & 100 & 40 \\
\hline HLMs & 0.05 & Dextromethorphan & 2.5 & 10 \\
\hline HLMs & 0.1 & Diltiazem & 30 & 15 \\
\hline HLMs & 0.05 & Luciferin-4A & 50 & 10 \\
\hline HRMs & $\begin{array}{c}0.1 \\
(\mathrm{pmol} / \mathrm{ml})\end{array}$ & Luciferin-4A & 50 & 10 \\
\hline CYP1A1 & 0.1 & 7-Ethoxyresorufin & 0.15 & 20 \\
\hline CYP1A2 & 0.3 & 7-Ethoxyresorufin & 0.15 & 10 \\
\hline CYP1B1 & 0.2 & 7-Ethoxyresorufin & 0.15 & 25 \\
\hline CYP2A6 & 10 & Coumarin & 2.5 & 21 \\
\hline CYP2B6 & 5 & 7-Benzoxyresorufin & 0.6 & 40 \\
\hline CYP2C8 & 40 & Dibenzylfluorescein & 0.4 & 40 \\
\hline CYP2C9 & 20 & $S$-Warfarin & 3 & 20 \\
\hline CYP2C19 & 40 & 3-O-Methylfluorescein & 4 & 24 \\
\hline CYP2D6 & 1.25 & Dextromethorphan & 0.6 & 10 \\
\hline CYP2E1 & 8 & Chlorzoxazone & 200 & 20 \\
\hline CYP2J2 & 5 & Luciferin-2J2/4F12 & 3 & 20 \\
\hline CYP3A4 & 10 & Diltiazem & 10 & 15 \\
\hline CYP3A5 & 10 & Diltiazem & 50 & 15 \\
\hline CYP4A11 & 10 & Luciferin-4A & 50 & 20 \\
\hline CYP4F2 & 20 & Luciferin-4F2/3 & 5 & 20 \\
\hline CYP4F3B & 10 & Luciferin-4F2/3 & 3 & 20 \\
\hline CYP4F12 & 20 & Luciferin-4F12 & 3 & 20 \\
\hline
\end{tabular}

dextromethorphan, chlorzoxazone, diltiazem, 7-hydroxycoumarin, dextrorphan, quinidine, ketoconazole, and epalrestat from Wako Pure Chemical Industries (Osaka, Japan); 6-hydroxychlorzoxazone from Corning (Woburn, MA); 4-nitrophenol from AccuStandard (New Haven, CT); $S$-mephenytoin from Toronto Research Chemicals (North York, ON, Canada); anti-human CYP4A11 IgG (product $\mathrm{Hu}-\mathrm{A} 007$, lot RaR/B3-7) and preimmune IgG (product Hu-A000, lot ABT) from CYP450-GP (Vista, CA); and NADP, glucose 6-phosphate, and glucose 6-phosphate dehydrogenase from Oriental Yeast (Tokyo, Japan). All other chemicals and solvents used were of the highest quality commercially available.

Enzyme Assay for Luciferin-4A O-Demethylation. Experimental conditions for the luciferin- $4 \mathrm{~A} O$-demethylase assay are shown in Table 1. Luciferin-4A $O$-demethylase activity was determined according to the instructions provided by Promega. All reactions were carried out at $37^{\circ} \mathrm{C}$ in a shaking water bath. HLMs $(0.05 \mathrm{mg}$ protein $/ \mathrm{ml})$, HRMs $(0.1 \mathrm{mg}$ protein $/ \mathrm{ml})$, and recombinant CYP4A11 $(10 \mathrm{pmol} / \mathrm{ml})$ were used as enzyme sources. Incubation tubes contained an enzyme source, $50 \mu \mathrm{M}$ luciferin-4A, a NADPH-generating system (0.5 mM NADP, $10 \mathrm{mM}$ glucose 6-phosphate, $10 \mathrm{mM}$ magnesium chloride, and $1 \mathrm{U} / \mathrm{ml}$ glucose 6-phosphate dehydrogenase), and $100 \mathrm{mM}$ potassium phosphate buffer $(\mathrm{pH} \mathrm{7.4})$ in a final volume of $200 \mu \mathrm{l}$. After prewarming at $37^{\circ} \mathrm{C}$ for 5 minutes, reactions were initiated by addition of the NADPH-generating system. Incubations were carried out at $37^{\circ} \mathrm{C}$ for 10 minutes ( 20 minutes for recombinant CYP4A11). An aliquot $(50 \mu \mathrm{l})$ of the incubation mixture was transferred to a luminometer tube containing $50 \mu \mathrm{l} \mathrm{LDR}$. After allowing to stand at room temperature for 20 minutes, luminescence was measured using a MiniLumat LB 9506 luminometer (EG\&G Berthold, Bad Wildbad, Germany).

To determine the kinetic parameters for luciferin-4A $O$-demethylation catalyzed by HLMs, HRMs, and recombinant CYP4A11, luciferin-4A (12.5-500 $\mu \mathrm{M})$ was incubated with each enzyme source under the same conditions as described above. In preliminary experiments, these reaction conditions were confirmed to ensure linear initial rates for luciferin formation. Data points were fitted to the Hill and Michaelis-Menten equations by nonlinear regression analysis with Origin 7.5J software (OriginLab, Northampton, MA).
Other Enzyme Assays. Experimental conditions for the other enzyme assays are shown in Table 1 . The 7-ethoxyresorufin $O$ deethylase activities of pooled HLMs, recombinant CYP1A1, CYP1A2, and CYP1B1 were determined, as described previously (Yamaori et al., 2010), except that HLMs were incubated with $0.5 \mu \mathrm{M}$ 7-ethoxyresorufin. The coumarin 7-hydroxylase activity of recombinant CYP2A6 and 7-benzoxyresorufin $O$-debenzylase activity of recombinant CYP2B6 were measured, as reported previously (Yamaori et al., 2011b). The activities of $S$-warfarin 7-hydroxylation catalyzed by pooled HLMs and recombinant CYP2C9 were determined, as described previously (Yamaori et al., 2012), except that HLMs were incubated with $6 \mu \mathrm{M} S$-warfarin. The $S$-mephenytoin 4-hydroxylase activity of pooled $\mathrm{HLMs}$ and 3-O-methylfluorescein $O$-demethylase activity of recombinant CYP2C19 were measured, as reported previously (Jiang et al., 2013), except that HLMs were incubated with $100 \mu \mathrm{M} S$-mephenytoin. The activities of dextromethorphan $O$-demethylation catalyzed by pooled HLMs and recombinant CYP2D6 were measured, as reported previously (Yamaori et al., 2011c), except that HLMs were incubated with $2.5 \mu \mathrm{M}$ dextromethorphan. The diltiazem $N$-demethylase activities of pooled HLMs, recombinant CYP3A4, and CYP3A5 were measured, as reported previously (Yamaori et al., 2011a), except that HLMs and recombinant CYP3A4 were incubated with 30 and $10 \mu \mathrm{M}$ diltiazem, respectively.

The dibenzylfluorescein $O$-debenzylase activity of recombinant CYP2C8 was determined by using 96 -well microtiter plates according to the protocol supplied by BD Gentest (San Jose, CA). Briefly, the incubation mixture consisted of an enzyme source, dibenzylfluorescein, a NADPH-generating system $(0.5 \mathrm{mM}$ NADP, $10 \mathrm{mM}$ glucose 6-phosphate, $10 \mathrm{mM}$ magnesium chloride, and $1 \mathrm{U} / \mathrm{ml}$ glucose 6-phosphate dehydrogenase), and $50 \mathrm{mM}$ potassium phosphate buffer ( $\mathrm{pH}$ 7.4) in a final volume of $200 \mu \mathrm{l}$. After prewarming at $37^{\circ} \mathrm{C}$ for 10 minutes, reactions were initiated by addition of the NADPH-generating system. Fluorescence derived from fluorescein formation was recorded every 5 minutes for 45 minutes using a FLUOstar OPTIMA (BMG Labtech, Offenburg, Germany) with excitation and emission wavelengths of 480 and $555 \mathrm{~nm}$, respectively.

The chlorzoxazone 6-hydroxylase activity of recombinant CYP2E1 was measured, as reported previously (Hanioka et al., 2007), with 
minor modifications. The incubation mixture consisted of the enzyme source, chlorzoxazone, NADPH-generating system, and $50 \mathrm{mM}$ potassium phosphate buffer $(\mathrm{pH}$ 7.4) in a final volume of $500 \mu$ l. After prewarming at $37^{\circ} \mathrm{C}$ for 5 minutes, reactions were initiated by addition of the NADPH-generating system. Incubations were carried out at $37^{\circ} \mathrm{C}$ for 20 minutes and terminated by adding $3 \mathrm{ml}$ ethyl acetate. Following addition of 4-nitrophenol $(2 \mathrm{nmol})$ as an internal standard, the mixture was extracted from ethyl acetate and the solvent was evaporated. The residue was dissolved in $100 \mu \mathrm{l}$ mobile phase, and $50 \mu \mathrm{l}$ supernatant was subjected to high-performance liquid chromatography (L-2100 pump, L-2200 autosampler, L-2300 column oven, and L-2400 UV detector; Hitachi, Tokyo, Japan) equipped with a Mightysil RP-18 GP II column $(2.0 \times 150 \mathrm{~mm}$, $5 \mu \mathrm{m}$; Kanto Chemical, Tokyo, Japan) maintained in a column oven at $40^{\circ} \mathrm{C}$. The mobile phase consisted of a mixture of $80 \mathrm{mM}$ acetic acid: acetonitrile (82:18). Elution was performed at a flow rate of $0.2 \mathrm{ml} / \mathrm{min}$. The formation of 6-hydroxychlorzoxazone was monitored at a wavelength of $295 \mathrm{~nm}$.

The luciferin-2J2/4F12 O-dealkylase activity of recombinant CYP2J2, luciferin-4F2/3 O-dealkylase activities of recombinant CYP4F2 and CYP4F3B, and luciferin-4F12 $O$-dealkylase activity of recombinant CYP4F12 were measured according to the instructions provided by Promega. All reactions were carried out at $37^{\circ} \mathrm{C}$ in a shaking water bath. Incubation tubes contained enzyme source, luciferin substrate, NADPH-generating system, and $100 \mathrm{mM}$ potassium phosphate buffer ( $\mathrm{pH} 7.4 ; 50 \mathrm{mM}$ for luciferin-4F2/3) in a final volume of $200 \mu \mathrm{l}$. After prewarming at $37^{\circ} \mathrm{C}$ for 5 minutes, reactions were initiated by addition of the NADPH-generating system. Incubations were carried out at $37^{\circ} \mathrm{C}$ for 20 minutes. An aliquot $(50 \mu \mathrm{l})$ of the incubation mixture was transferred to a luminometer tube containing $50 \mu \mathrm{l} \mathrm{LDR} \mathrm{(LDR} \mathrm{with} \mathrm{esterase} \mathrm{for} \mathrm{luciferin-2J2/4F12).}$ After allowing to stand at room temperature for 20 minutes, luminescence was measured using a MiniLumat LB 9506 luminometer (EG\&G Berthold).

Inhibition Studies with Chemical Inhibitors. Pooled HLMs, pooled HRMs, and recombinant CYP enzymes were incubated with substrate in the presence of test compounds, including epalrestat, in the same manner as described for the enzyme assays. With the exception of tranylcypromine, thio-TEPA, quinidine, and diethyldithiocarbamate that were dissolved in water, all compounds used were dissolved in dimethylsulfoxide (DMSO) and added to the incubation mixture at a final DMSO concentration of $\leq 0.5 \%$. Residual DMSO $(\leq 0.5 \%)$ in incubation mixtures caused less than $8 \%$ inhibition of luciferin-4A $O$-demethylase activity under the conditions used in the present study. The $\mathrm{IC}_{50}$ values were calculated by nonlinear regression analysis with GraphPad Prism 5.02 (GraphPad Software, San Diego, CA), using the dose response with variable slope function.

The effects of four different inhibitor concentrations on luciferin-4A $O$-demethylation were investigated at five substrate concentrations to characterize the enzyme kinetics for inhibition of CYP4A11 by epalrestat. Data points were fitted to the Hill equation by nonlinear regression analysis with Origin 7.5J software (OriginLab) to estimate the mode of inhibition. The apparent $K_{\mathrm{i}}$ values were determined from inhibition model of the Michaelis-Menten kinetics by nonlinear regression analysis with GraphPad Prism 5.02 (GraphPad Software).

To identify potential metabolism-dependent inhibition of CYP4A11 by epalrestat, the inhibition experiments were performed, as described below. The preincubation mixture contained recombinant CYP4A11 (10 pmol/ml), epalrestat $(0-10 \mu \mathrm{M})$, the NADPHgenerating system, and $100 \mathrm{mM}$ potassium phosphate buffer $\left(\mathrm{pH}\right.$ 7.4) in a final volume of $180 \mu \mathrm{l}$. After prewarming at $37^{\circ} \mathrm{C}$ for 5 minutes, reactions were initiated by addition of the NADPHgenerating system. Following 20-minute preincubation, $20 \mu \mathrm{l}$ luciferin-4A solution was added to the preincubation mixture (final substrate concentration $50 \mu \mathrm{M}$ ). Incubations were conducted in the same manner as described for the luciferin-4A $O$-demethylase activity enzyme assay.
Inhibition Study with Anti-CYP4A11 Antibody. The antibody inhibition assay was carried out according to the instructions for CYP450-GP. Pooled HLMs (0.05 mg protein $/ \mathrm{ml})$, pooled HRMs $(0.1 \mathrm{mg}$ protein $/ \mathrm{ml})$, recombinant CYP4A11 $(10 \mathrm{pmol} / \mathrm{ml})$, recombinant CYP4F2 $(20 \mathrm{pmol} / \mathrm{ml})$, recombinant CYP4F3B $(10 \mathrm{pmol} / \mathrm{ml})$, or recombinant CYP4F12 $(20 \mathrm{pmol} / \mathrm{ml})$ was preincubated with antihuman CYP4A11 IgG and preimmune IgG $(0-1 \mathrm{mg}$ IgG of antihuman CYP4A11 antibody/mg protein in HLMs and HRMs, 0-5 mg IgG of anti-human CYP4A11 antibody/nmol P450 in recombinant CYP4 enzymes) in a shaking water bath at $37^{\circ} \mathrm{C}$ for 3 minutes. After allowing to stand at room temperature for 10 minutes, the incubation tube was placed on ice. Prewarming was started by adding luciferin$4 \mathrm{~A}$ (final concentration $50 \mu \mathrm{M}$ ), luciferin- $4 \mathrm{~F} 2 / 3$ (final concentration $5 \mu \mathrm{M}$ for CYP4F2, $3 \mu \mathrm{M}$ for CYP4F3B), or luciferin-4F12 (final concentration $3 \mu \mathrm{M}$ ), and potassium phosphate buffer (final concentration $100 \mathrm{mM}$ for luciferin-4A and luciferin-4F12, $50 \mathrm{mM}$ for luciferin-4F2/3; $\mathrm{pH} 7.4$ ) to the corresponding preincubation mixture. After prewarming at $37^{\circ} \mathrm{C}$ for 5 minutes, reactions were initiated by adding the NADPH-generating system. Luciferin-4A $O$-demethylase activities of HLMs, HRMs, and recombinant CYP4A11; luciferin4F2/3 $O$-dealkylase activities of recombinant CYP4F2 and CYP4F3B; and luciferin-4F12 $O$-dealkylase activity of recombinant CYP4F12 were determined, as described above.

Statistical Analysis. The correlations between catalytic activities of HLMs were determined by Pearson's correlation coefficients with GraphPad Prism 5.02 (GraphPad Software).

\section{Results}

Kinetic Analysis of Luciferin-4A $O$-Demethylation by HLMs and HRMs. Kinetic analysis was carried out with pooled HLMs, pooled HRMs, and recombinant CYP4A11 to clarify whether HLMs and HRMs exhibit luciferin-4A $O$ demethylation activity. Kinetic parameters were determined from the Hill and Michaelis-Menten equations, and were compared with each other. All of the reactions examined were fitted to the Hill model better than the Michaelis-Menten model based on the coefficients of determination (Table 2). The Hill coefficients for HLMs, HRMs, and recombinant CYP4A11 were $1.24,1.34$, and 1.23 , respectively (Table 2 ), indicating a small but positive cooperativity. The slight curvatures were apparent in the Eadie-Hofstee plots (Fig. 2). Collectively, the luciferin-4A $O$-demethylation catalyzed by HLMs, HRMs, and recombinant CYP4A11 followed Hill kinetics. The $V_{\max }$ values for HLMs, HRMs, and recombinant CYP4A11 were $39.7 \mathrm{pmol} / \mathrm{min}$ per milligram protein, $39.4 \mathrm{pmol} / \mathrm{min}$ per milligram protein, and $656 \mathrm{pmol} / \mathrm{min}$ per nanomoles P450, respectively (Table 2 ). The $S_{50}$ values for HLMs, HRMs, and recombinant CYP4A11 were 43.2, 33.8 , and $29.1 \mu \mathrm{M}$, respectively (Table 2).

Effects of Selective CYP Inhibitors and AntiCYP4A11 Antibody on Luciferin-4A $O$-Demethylase Activity of HLMs and HRMs. To determine the involvement of CYP4 enzyme(s) in luciferin-4A $O$-demethylation catalyzed by HLMs and HRMs, the effects of selective inhibitors of CYP isoforms on the catalytic activity were examined at a substrate concentration of $50 \mu \mathrm{M}$. Among the inhibitors tested, only HET0016, a CYP4 inhibitor, effectively inhibited luciferin-4A $O$-demethylase activity of HLMs and HRMs as well as recombinant CYP4A11 (Fig. 3). In contrast, $\alpha$-naphthoflavone (CYP1 inhibitor), tranylcypromine (CYP2A6 inhibitor), thio-TEPA (CYP2B6 inhibitor), trimethoprim (CYP2C8 inhibitor), sulfaphenazole (CYP2C9 inhibitor), (-)- $N$-3-benzyl-phenobarbital (CYP2C19 inhibitor), quinidine (CYP2D6 inhibitor), diethyldithiocarbamate (CYP2E1 
TABLE 2

Kinetic parameters for luciferin-4A $O$-demethylation catalyzed by HLMs, HRMs, and recombinant CYP4A11

Data points were fitted to the Hill and Michaelis-Menten (MM) models. Values of $V_{\max }, S_{50}$ (substrate concentration to give $50 \%$ of $\left.V_{\max }\right) / K_{\mathrm{m}}$, and $n$ (Hill coefficient for cooperative binding) are means \pm S.E. of kinetic parameters.

\begin{tabular}{lcccrr}
\hline \multicolumn{1}{c}{ Enzymes } & Models & $V_{\max }$ & $S_{50} / K_{\mathrm{m}}$ & $n$ & $R^{2 a}$ \\
\hline \multirow{3}{*}{ HLMs } & & $($ pmol/min per milligram protein) & $(\mu \mathrm{M})$ & & \\
& Hill & $39.7 \pm 1.3$ & $43.2 \pm 3.2$ & $1.24 \pm 0.09$ & 0.992 \\
HRMs & MM & $44.2 \pm 1.2$ & $54.9 \pm 4.1$ & - & 0.987 \\
& Hill & $39.4 \pm 1.3$ & $33.8 \pm 2.7$ & $1.34 \pm 0.13$ & 0.977 \\
& MM & $42.5 \pm 1.4$ & $39.2 \pm 4.3$ & - & 0.963 \\
CYP4A11 & Hill & $(\mathrm{pmol} /$ min per nanomoles P450) & & \\
& MM & $656 \pm 14$ & $29.1 \pm 1.5$ & $1.23 \pm 0.08$ & 0.993 \\
& & $705 \pm 13$ & $33.6 \pm 2.1$ & - & 0.988 \\
\hline
\end{tabular}

${ }^{a}$ Coefficient of determination.

inhibitor), and ketoconazole (CYP3A inhibitor) were unable to significantly inhibit the luciferin-4A $O$-demethylase activity. HET0016 inhibited the catalytic activity of HLMs, HRMs, and recombinant CYP4A11 in a concentrationdependent manner (Supplemental Fig. 1), with $\mathrm{IC}_{50}$ values (mean \pm S.E.) of $0.0333 \pm 0.0035,0.0213 \pm 0.0010$, and $0.0172 \pm 0.0005 \mu \mathrm{M}$, respectively.

As noted in the Introduction, however, HET0016 is not a chemical inhibitor selective for CYP4A11. Therefore, we investigated the effects of anti-CYP4A11 antibody on the
A

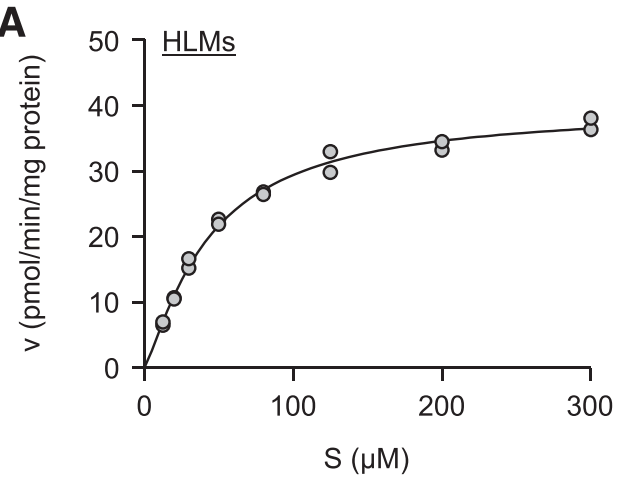

C

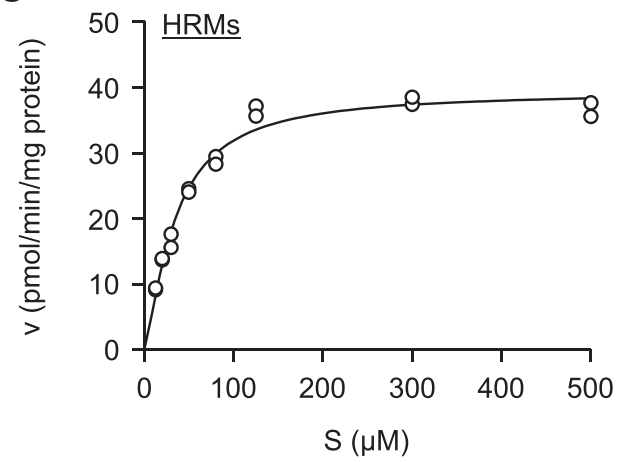

E

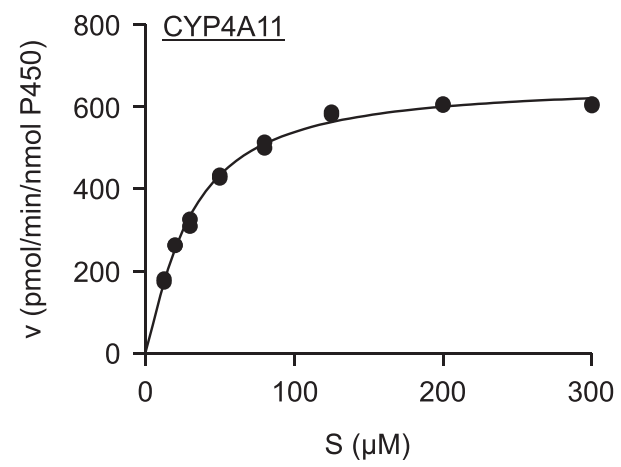

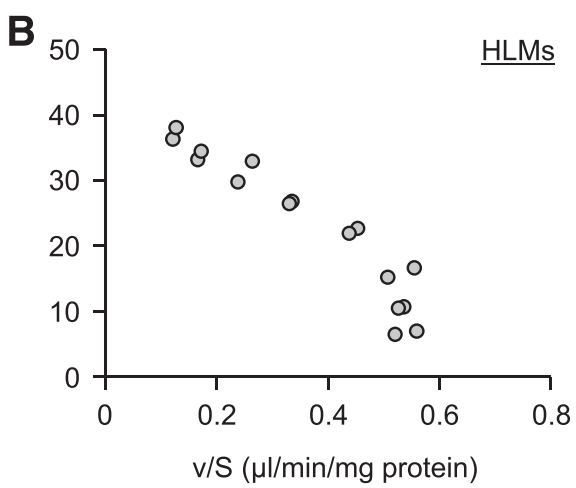

D

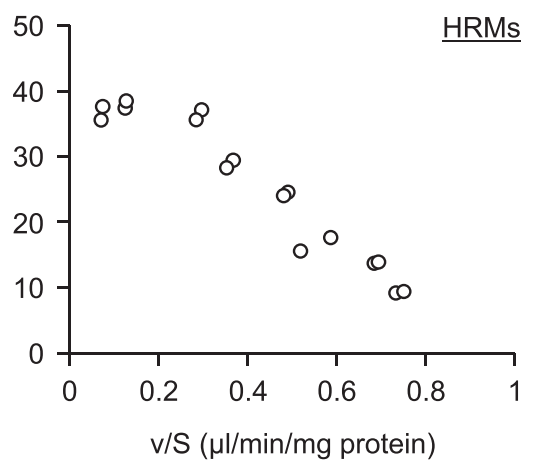

$\mathbf{F}$

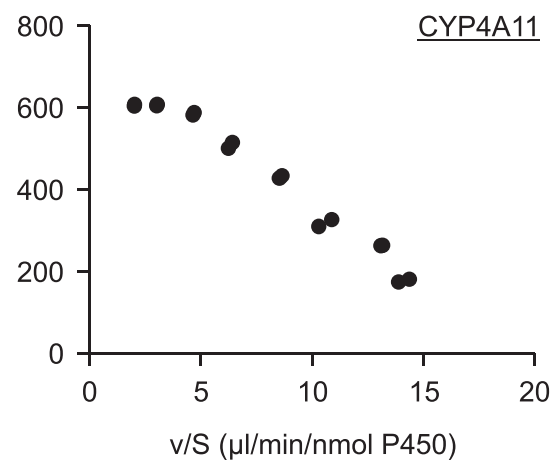

Fig. 2. Kinetic analyses to examine the luciferin-4A $O$-demethylase activities of HLMs, HRMs, and recombinant CYP4A11. Pooled HLMs (A and B), pooled HRMs (C and D), and recombinant CYP4A11 (E and $\mathrm{F}$ ) were incubated with luciferin-4A (12.5-500 $\mu \mathrm{M})$. (A, C, and E) Hill plots. (B, D, and F) Eadie-Hofstee plots. $\mathrm{S}$ and $\mathrm{v}$ indicate luciferin- $4 \mathrm{~A}$ and catalytic activity, respectively. Each point indicates an individual value. 
A

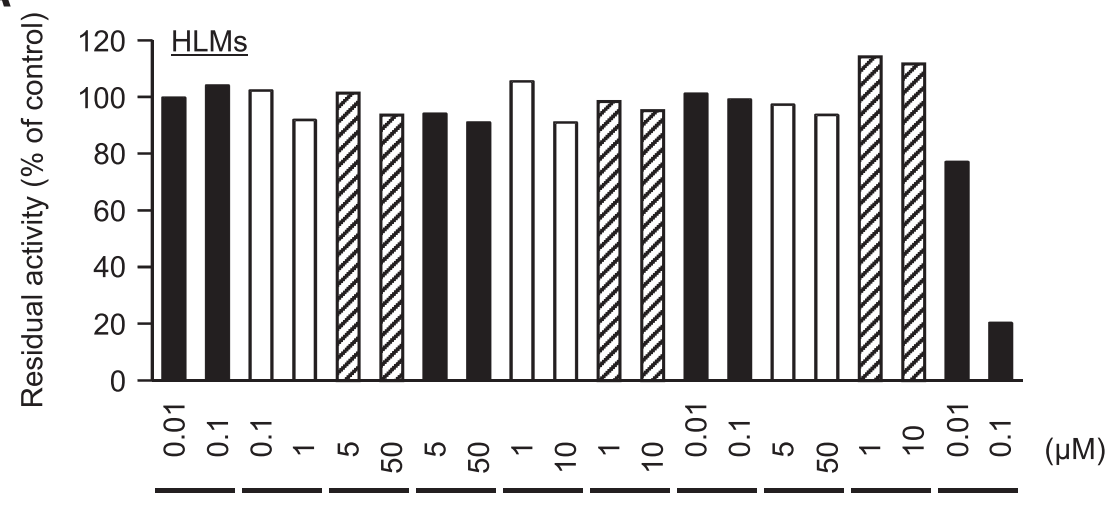

B

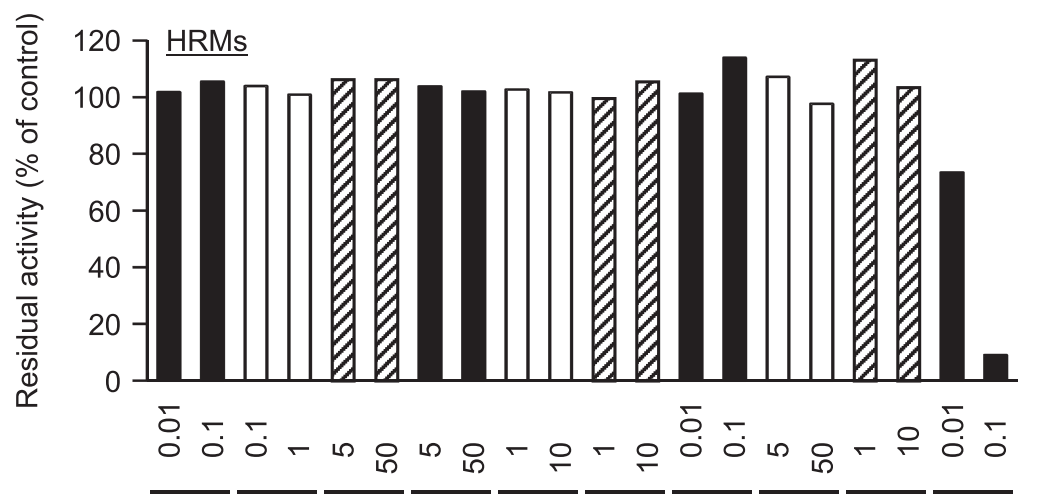

C

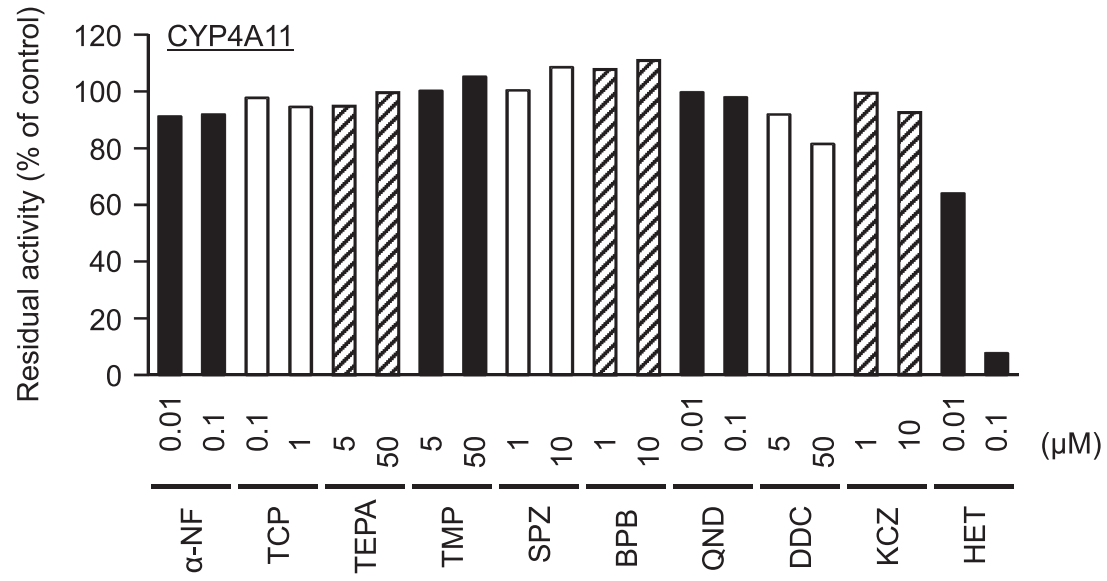

Fig. 3. Effects of various CYP inhibitors on luciferin4A $O$-demethylase activities of HLMs, HRMs, and recombinant CYP4A11. Pooled HLMs (A), pooled HRMs (B), and recombinant CYP4A11 (C) were incubated with $50 \mu \mathrm{M}$ luciferin- $4 \mathrm{~A}$ in the presence of various amounts of representative CYP inhibitors. Each point is the mean of duplicate determinations. $\mathrm{BPB},(-)-N$-3-benzyl-phenobarbital; DDC, diethyldithiocarbamate; HET, HET0016; KCZ, ketoconazole; $\alpha$-NF, $\alpha$-naphthoflavone; QND, quinidine; SPZ, sulfaphenazole; TCP, tranylcypromine; TEPA, thioTEPA; TMP, trimethoprim.
luciferin-4A $O$-demethylase activity of HLMs and HRMs. The results indicated that anti-CYP4A11 antibody almost completely inhibited the catalytic activity of both tissue microsomes as well as recombinant CYP4A11 (Fig. 4). In contrast, anti-CYP4A11 antibody did not influence catalytic activities of recombinant CYP4F2, CYP4F3B, and CYP4F12, indicating the high specificity of this antibody (Supplemental Fig. 2).

Correlation between Luciferin-4A $O$-Demethylase and CYP Isoform-Specific Activities in HLMs. The luciferin-4A $O$-demethylase activity was determined with 16 individual HLMs and compared with CYP-isoform marker activities measured by XenoTech. Luciferin-4A $O$-demethylation was strongly correlated with lauric acid $\omega$-hydroxylation ( $r=0.904, P<0.0001$ ), an index of CYP4A11 activity (Fig. 5).
In addition, luciferin-4A $O$-demethylation was positively correlated with 7-ethoxyresorufin $O$-deethylation $(r=0.628$, $P<0.01$ ), an index of CYP1A2 activity, whereas it was negatively correlated with dextromethorphan $O$-demethylation $(r=-0.620, P<0.05)$, an index of CYP2D6 activity (Table 3 ).

Effects of Epalrestat on Individual CYP Activities of Recombinant CYP Enzymes. To characterize the isoform selectivity of epalrestat-mediated inhibition, the effects of epalrestat on various drug oxidation activities at substrate concentrations close to the $K_{\mathrm{m}}$ values were investigated with recombinant CYP enzymes. Epalrestat showed the most potent inhibition of CYP4A11 activity with an $\mathrm{IC}_{50}$ value (mean \pm S.E.) of $1.82 \pm 0.04 \mu \mathrm{M}$, although the drug moderately inhibited the catalytic activities of CYP2C8, 

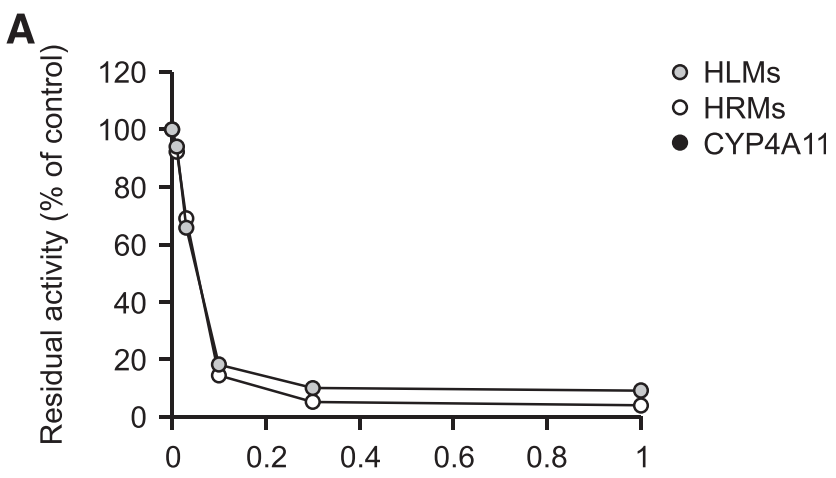

Antibody : microsomal protein ratio (mg anti-human CYP4A11 lgG/mg protein)

B

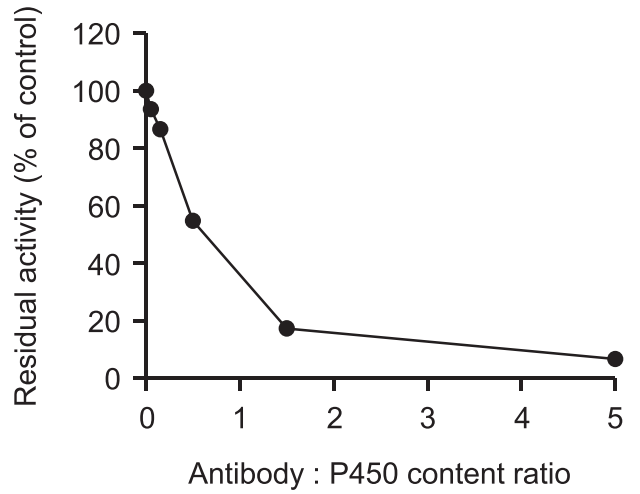

(mg anti-human CYP4A11 lgG/nmol P450)

Fig. 4. Effects of anti-CYP4A11 antibody on luciferin-4A $O$-demethylase activities of HLMs, HRMs, and recombinant CYP4A11. Pooled HLMs (A), pooled HRMs (A), and recombinant CYP4A11 (B) were preincubated with anti-human CYP4A11 IgG and preimmune IgG $(0-1 \mathrm{mg}$ IgG of antihuman CYP4A11 antibody/mg protein in HLMs and HRMs, 0-5 mg IgG of anti-human CYP4A11 antibody/nmol P450 in recombinant CYP4A11) and then incubated with $50 \mu \mathrm{M}$ luciferin-4A in the presence of NADPH. Each point is the mean of duplicate determinations.

CYP2C9, CYP4F2, CYP4F3B, and CYP4F12 with $\mathrm{IC}_{50}$ values of $32.8 \pm 1.9,19.8 \pm 1.4,35.9 \pm 1.3,19.9 \pm 1.0$, and $38.7 \pm 2.3$ $\mu \mathrm{M}$, respectively (Fig. 6). Epalrestat showed no or weak inhibition against CYP1A1, CYP1A2, CYP1B1, CYP2A6, CYP2B6, CYP2C19, CYP2D6, CYP2E1, CYP2J2, CYP3A4, and CYP3A5 with $\mathrm{IC}_{50}$ values $>50 \mu \mathrm{M}$.

Comparison of Inhibitory Effects of Epalrestat and Known CYP4 Inhibitors on Catalytic Activities of Recombinant CYP4A11 and CYP4F Enzymes. To characterize the selectivity of CYP4A11 inhibition by epalrestat, the inhibitory effects of known CYP4 inhibitors on CYP4A11, CYP4F2, CYP4F3B, and CYP4F12 activities were investigated with recombinant CYP enzymes and compared with those of epalrestat. HET0016 showed more potent inhibition of CYP4A11 and CYP4F2 activities than CYP4F3B and CYP4F12 activities (Fig. 7A). The inhibitory effect of HET0016 on CYP4A11 activity was approximately equivalent to that on CYP4F2 activity (Table 4). The 17-ODYA inhibited the activities of CYP4A11, CYP4F2, CYP4F3B, and CYP4F12 to a similar extent (Fig. 7B; Table 4). In contrast, the inhibitory effect of epalrestat on CYP4A11 activity was at least 10-fold more potent than those on CYP4F2, CYP4F3B, and CYP4F12 activities (Table 4).

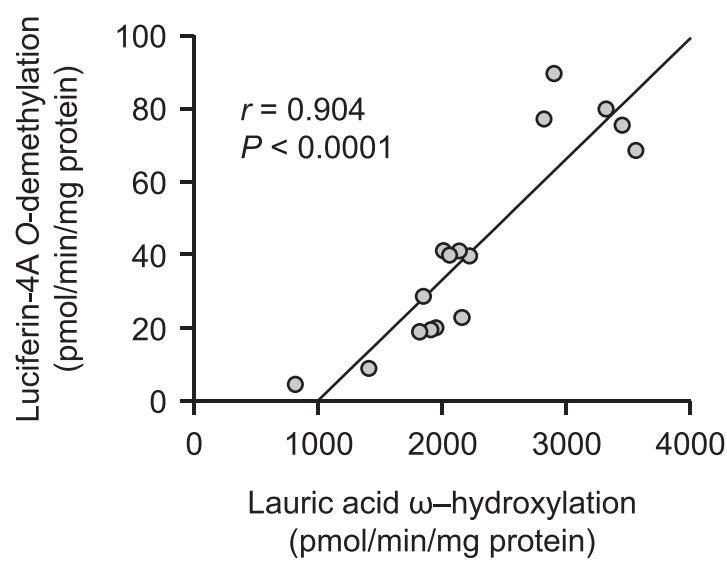

Fig. 5. Relationship of luciferin-4A $O$-demethylase activity with lauric acid $\omega$-hydroxylase activity in HLMs. Sixteen individual HLMs were incubated with $50 \mu \mathrm{M}$ luciferin-4A. Lauric acid $\omega$-hydroxylase activity was measured by XenoTech. Each point indicates the mean of duplicate determinations.

Effects of Epalrestat on CYP Activities of HLMs and HRMs. To elucidate the CYP4A11 selectivity of epalrestatmediated inhibition in HLMs, the effects of epalrestat on luciferin-4A $O$-demethylation and representative drug oxidation activities at substrate concentrations close to the $K_{\mathrm{m}}$ values were examined with pooled HLMs. Epalrestat strongly inhibited the luciferin- $4 \mathrm{~A} O$-demethylation with an $\mathrm{IC}_{50}$ value (mean \pm S.E.) of $0.913 \pm 0.032 \mu \mathrm{M}$, although the drug moderately inhibited the $S$-warfarin 7-hydroxylation, a marker activity of CYP2C9, with the $\mathrm{IC}_{50}$ value of $23.7 \pm 0.8$ $\mu \mathrm{M}$ (Fig. 8). Epalrestat exhibited no or weak inhibition against 7-ethoxyresorufin $O$-deethylation (marker activity of CYP1A2), $S$-mephenytoin 4-hydroxylation (marker activity of CYP2C19), dextromethorphan $O$-demethylation (marker activity of CYP2D6), and diltiazem $N$-demethylation (marker activity of CYP3A4/5) with $\mathrm{IC}_{50}$ values $>50 \mu \mathrm{M}$. The effect of epalrestat on luciferin-4A $O$-demethylase activity of HRMs was also examined. Epalrestat showed a concentrationdependent inhibitory effect on the catalytic activity of pooled HRMs with the $\mathrm{IC}_{50}$ value of $0.659 \pm 0.028 \mu \mathrm{M}$ (Supplemental Fig. 3).

Kinetic Analysis of the Inhibition of CYP4A11 Activity by Epalrestat. To determine the mode of epalrestat-mediated inhibition of CYP4A11 activity, kinetic analysis of the inhibition was carried out with pooled HLMs, pooled HRMs, and recombinant CYP4A11. At first, the luciferin-4A $O$-demethylation by these enzyme sources was

TABLE 3

Correlation of luciferin-4A $O$-demethylase activity with CYP-isoform marker activities in 16 individual HLMs

\begin{tabular}{lcc}
\hline \multicolumn{1}{c}{ Isoforms } & \multicolumn{1}{c}{ Reactions } & $r$ \\
\hline CYP1A2 & 7-Ethoxyresorufin $O$-deethylation & $0.628^{* *}$ \\
CYP2A6 & Coumarin 7-hydroxylation & 0.372 \\
CYP2B6 & $S$-Mephenytoin $N$-demethylation & 0.052 \\
CYP2C8 & Paclitaxel 6 $\alpha$-hydroxylation & 0.133 \\
CYP2C9 & Diclofenac 4'-hydroxylation & -0.204 \\
CYP2C19 & $S$-Mephenytoin 4-hydroxylation & 0.257 \\
CYP2D6 & Dextromethorphan $O$-demethylation & $-0.620^{*}$ \\
CYP2E1 & Chlorzoxazone 6-hydroxylation & -0.373 \\
CYP3A4/5 & Testosterone 6 $\beta$-hydroxylation & 0.357 \\
\hline
\end{tabular}

$* P<0.05 ; * * P<0.01$ 
A

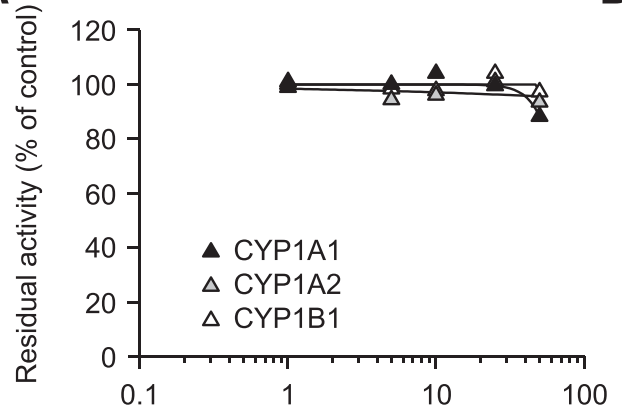

B

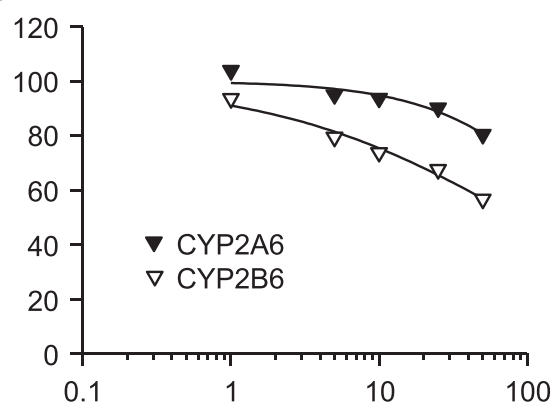

C

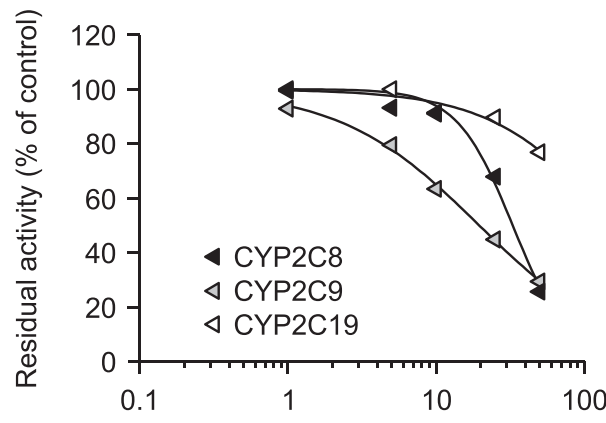

E

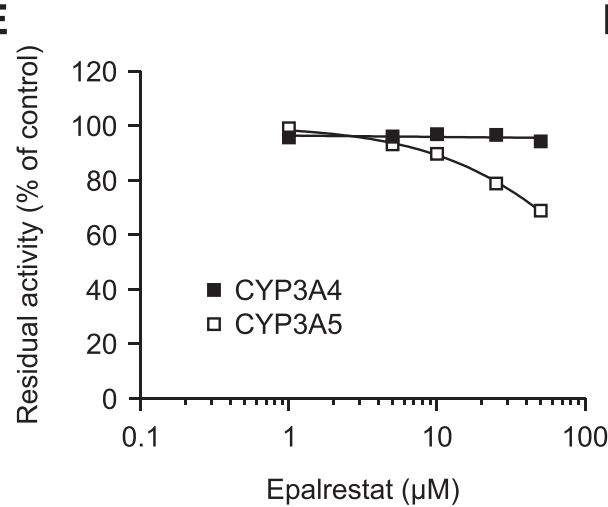

D

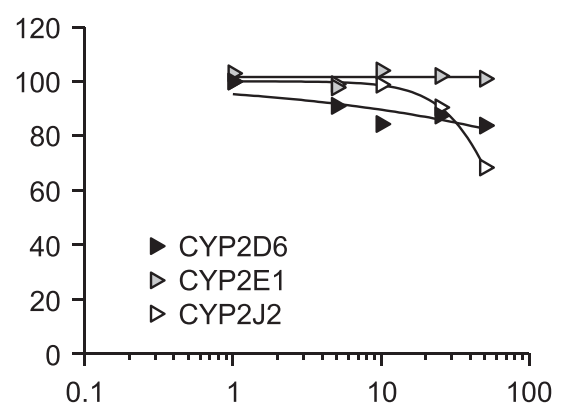

$\mathbf{F}$

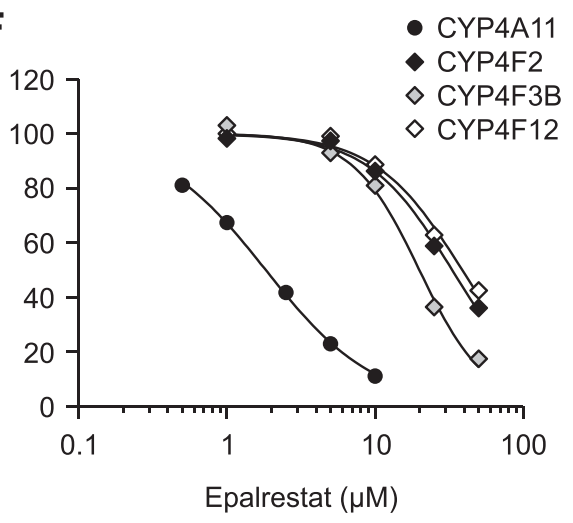

Fig. 6. Effects of epalrestat on various drug oxidations catalyzed by individual recombinant CYP enzymes. Recombinant CYP1A1 (A), CYP1A2 (A), CYP1B1 (A), CYP2A6 (B), CYP2B6 (B), CYP2C8 (C), CYP2C9 (C), CYP2C19 (C), CYP2D6 (D), CYP2E1 (D), CYP2J2 (D), CYP3A4 (E), CYP3A5 (E), CYP4A11 (F), CYP4F2 (F), CYP4F3B (F), and CYP4F12 (F) were incubated with respective CYP-isoform marker substrates in the presence of various amounts of epalrestat. Each point is the mean of duplicate determinations. fitted to the Hill model (Supplemental Fig. 4). In all of the reactions analyzed, $V_{\max }$ values decreased and $S_{50}$ values increased as the epalrestat concentration increased, whereas Hill coefficients did not change substantially (Supplemental Table 1). These results indicated that epalrestat inhibited the luciferin-4A $O$-demethylase activity of HLMs, HRMs, and recombinant CYP4A11 in a mixed fashion. Because an inhibition model of Hill kinetics was not available, these apparent $K_{\mathrm{i}}$ values were expediently determined from the mixed model inhibition of Michaelis-Menten kinetics. The apparent $K_{\mathrm{i}}$ values for HLMs, HRMs, and recombinant CYP4A11 were $0.349,0.198$, and $0.824 \mu \mathrm{M}$, respectively (Table 5).

Metabolism-Dependent Inhibition of CYP4A11 Activity by Epalrestat. To clarify whether epalrestat inhibits CYP4A11 activity in a metabolism-dependent manner, the effect of preincubation on epalrestat-mediated inhibition was examined with recombinant CYP4A11. A 20-minute preincubation of epalrestat in the presence of NADPH attenuated the inhibition of CYP4A11 activity (Fig. 9). The $\mathrm{IC}_{50}$ values (mean \pm S.E.) without and with preincubation were $1.85 \pm 0.06$ and $3.80 \pm 0.17 \mu \mathrm{M}$, respectively.

\section{Discussion}

A previous study has shown that the luciferin-4A $O$-demethylase activity of recombinant CYP4A11 variants is useful for high-throughput screening assay (Choi et al., 2013). However, it remains unclear whether this activity is a good probe substrate for human tissue microsomal CYP4A11. Therefore, we investigated the contribution of CYP4A11 to luciferin-4A $O$-demethylation catalyzed by HLMs and HRMs.

An autoactivation of luciferin-4A $O$-demethylation by recombinant CYP4A11 suggests the presence of two or more binding sites of luciferin-4A within the CYP4A11 molecule. In this case, the binding of a luciferin- $4 \mathrm{~A}$ molecule is considered to increase the affinity of other binding site(s). The results of kinetic analysis indicated that HLMs and HRMs also followed the same kinetics. In addition, the $S_{50}$ values for HLMs and HRMs were similar to that for recombinant CYP4A11. These results suggest the involvement of a certain enzyme, CYP4A11, in this reaction. This hypothesis was supported by the results of inhibition studies with selective chemical inhibitors and anti-CYP4A11 antibody. Furthermore, the 

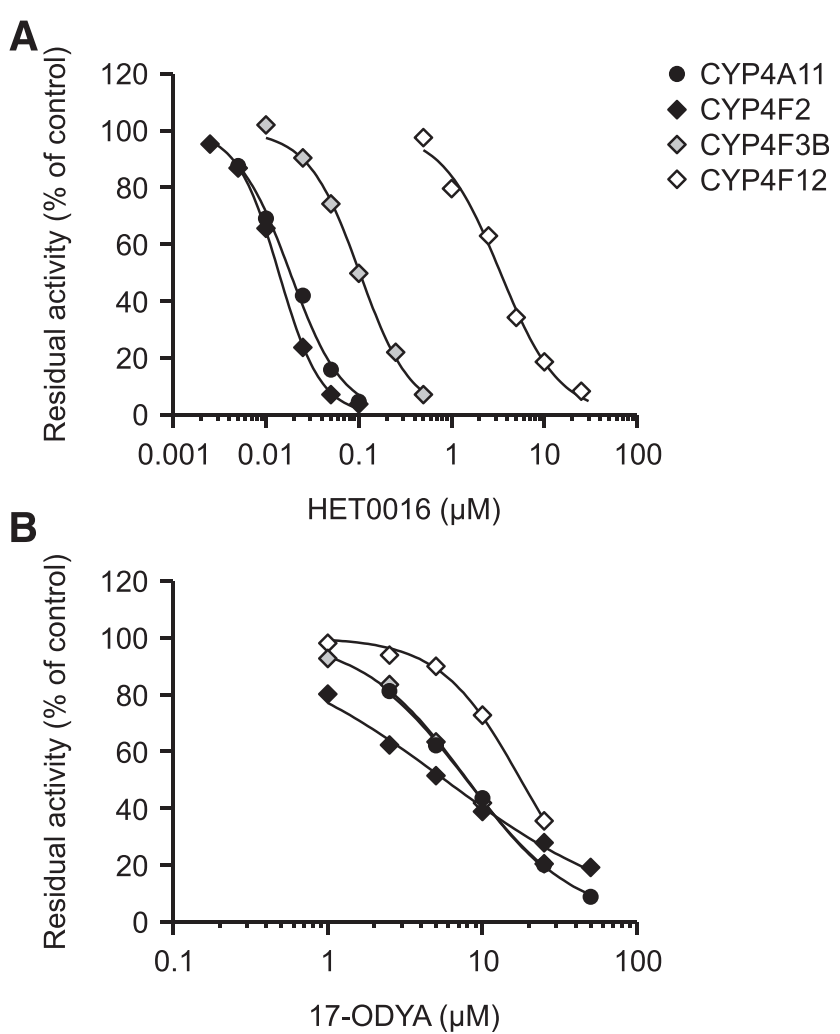

Fig. 7. Inhibitory effects of HET0016 and 17-ODYA on catalytic activities of CYP4A11, CYP4F2, CYP4F3B, and CYP4F12. Recombinant CYP4A11, CYP4F2, CYP4F3B, and CYP4F12 were incubated with the respective CYPisoform marker substrates in the presence of various amounts of HET0016 (A) and 17-ODYA (B). Each point is the mean of duplicate determinations.

luciferin-4A $O$-demethylase activities of individual HLMs were strongly correlated with lauric acid $\omega$-hydroxylase activity. These results suggest that CYP4A11 may be the major enzyme responsible for luciferin-4A $O$-demethylation catalyzed by HLMs and HRMs.

A good positive correlation of luciferin-4A $O$-demethylase and lauric acid $\omega$-hydroxylase activities had a large nonzero intercept. It has been previously reported that lauric acid $\omega$-hydroxylation is catalyzed by CYP4A (high affinity) and CYP3A (low affinity) in HLMs (Clarke et al., 1994). The involvement of multiple enzymes in lauric acid $\omega$-hydroxylation may be one of the reasons that the correlation with a large nonzero intercept was observed. Next, the luciferin-4A $O$ demethylase activity showed a significant positive correlation with the marker activity of CYP1A2. This was thought to be a false positive due to the significant correlation between the CYP1A2 and CYP4A11 marker activities measured by
XenoTech $(r=0.688, P<0.01$, data not shown). In fact, $\alpha$-naphthoflavone, a potent CYP1 inhibitor, did not affect the luciferin-4A $O$-demethylase activity of HLMs at all. Therefore, we excluded the possibility that CYP1A2 contributes to the luciferin-4A $O$-demethylation in HLMs, although recombinant CYP1A2 had only modest activity (https:// www.promega.jp/resources/pubhub/enotes/selective-cytochromep450-4a11-enzyme-assay-using-a-novel-bioluminescent-probesubstrate/). In this study, the luciferin-4A $O$-demethylase activity exhibited a significant negative correlation with the marker activity of CYP2D6. This result provides the possibility that CYP2D6 might undergo further metabolism of an $O$-demethylated metabolite of luciferin-4A. However, quinidine, a potent CYP2D6 inhibitor, did not increase formation of the $O$-demethylated metabolite when incubated with HLMs. Moreover, the CYP2D6 marker activity tended to be negatively correlated with the CYP4A11 marker activity measured by XenoTech $(r=-0.452, P=$ 0.08 , data not shown). Thus, this negative correlation with CYP2D6 might be a false positive, although we cannot absolutely exclude the possibility of further metabolism of the luciferin-4A metabolite by CYP2D6.

Lauric acid is a good probe substrate of CYP4A11 in vitro (Powell et al., 1996; Amet et al., 1997). However, a previous kinetic study suggested the involvement of more than one enzyme in HLM-mediated lauric acid $\omega$-hydroxylation, with CYP4A as a high-affinity enzyme and CYP3A as a low-affinity enzyme (Clarke et al., 1994). Furthermore, it has recently been reported that lauric acid $\omega$-hydroxylation is catalyzed not only by recombinant CYP4A11 but also by recombinant CYP4F2, CYP4F3A, and CYP4F3B, although the contributions of CYP4F2, CYP4F3A, and CYP4F3B to its oxidation in HLMs were estimated to be small (Choi et al., 2018). In contrast, luciferin-4A $O$-demethylation was shown to be catalyzed exclusively by CYP4A11 among the recombinant CYP4 enzymes tested (i.e., CYP4A11, CYP4F2, CYP4F3A, CYP4F3B, and CYP4F12) (https://www.promega.jp/resources/ pubhub/enotes/selective-cytochrome-p450-4a11-enzyme-assayusing-a-novel-bioluminescent-probe-substrate/). These findings and our results suggest that the luciferin-4A $O$-demethylase activity may be a CYP4A11-specific marker of HLMs and HRMs. This marker activity may provide useful information regarding the presence and function of CYP4A11 in microsomes from tissues other than the liver and kidneys.

The search for chemical inhibitors selective for CYP4A11 is very important to clarify its roles in (patho)physiologic functions and drug metabolism. Although several CYP4 inhibitors, such as 17-ODYA and HET0016, have been developed (Edson and Rettie, 2013), no chemical inhibitors entirely selective for CYP4A11 have yet been found. In this

TABLE 4

$\mathrm{IC}_{50}$ values of epalrestat, HET0016, and 17-ODYA for inhibition of CYP4F2, CYP4F3B, and CYP4F12 activities

Values (micromolars) are means \pm S.E. of kinetic parameters. The numbers in parentheses indicate ratios of $\mathrm{IC}_{50}$ values for CYP4F2, CYP4F3B, and CYP4F12 relative to the corresponding IC $_{50}$ values for CYP4A11.

\begin{tabular}{lccc}
\hline Isoforms & Epalrestat & HET0016 & 17-ODYA \\
\hline CYP4A11 & $1.82 \pm 0.04(1.00)$ & $0.0182 \pm 0.0010(1.00)$ & $7.88 \pm 0.18(1.00)$ \\
CYP4F2 & $35.9 \pm 1.3(19.7)$ & $0.0137 \pm 0.0003(0.753)$ & $5.70 \pm 0.35(0.723)$ \\
CYP4F3B & $19.9 \pm 1.0(10.9)$ & $0.102 \pm 0.005(5.60)$ & $7.97 \pm 0.28(1.01)$ \\
CYP4F12 & $38.7 \pm 2.3(21.3)$ & $3.36 \pm 0.24(185)$ & $17.7 \pm 0.6(2.25)$ \\
\hline
\end{tabular}



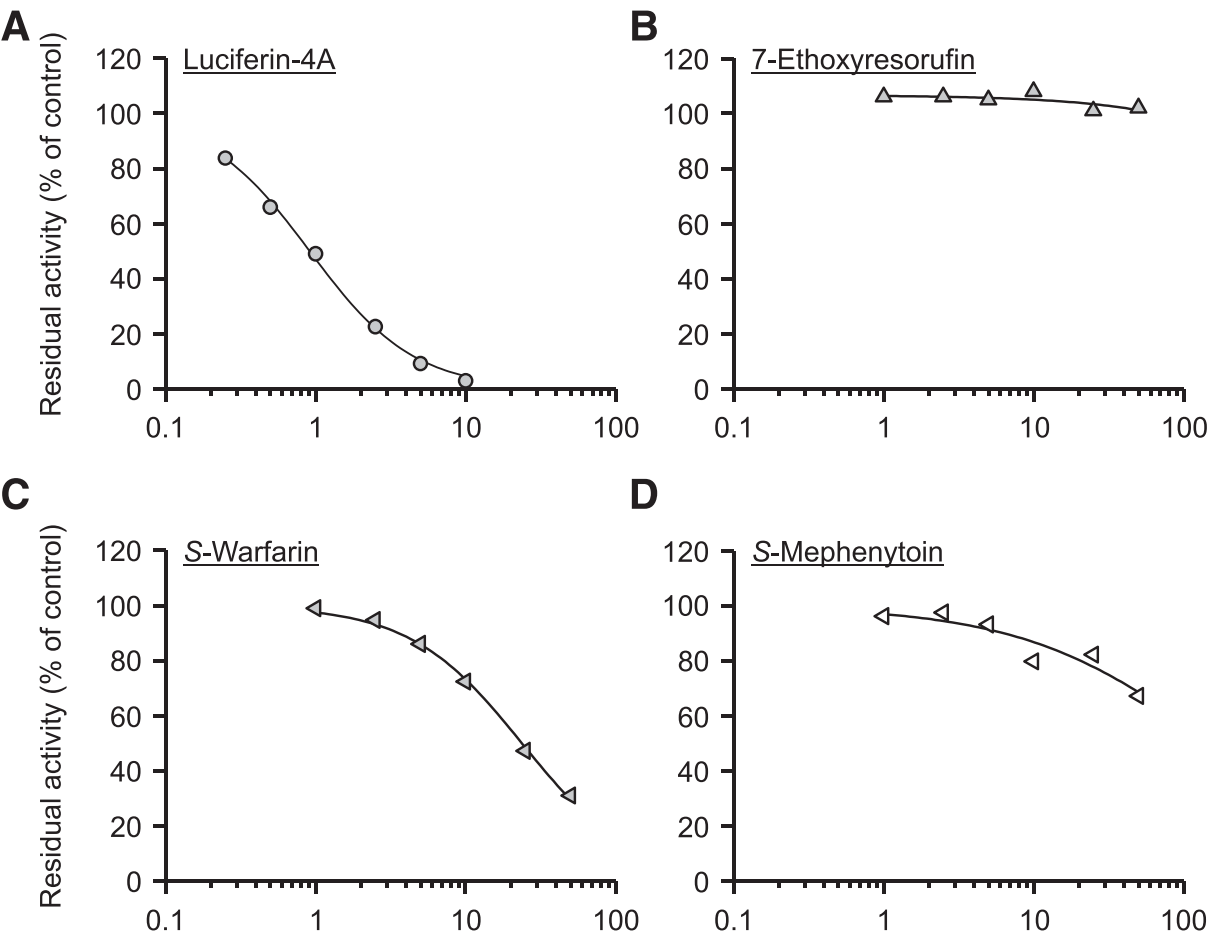

Fig. 8. Effects of epalrestat on various drug oxidation activities of HLMs. Pooled HLMs were incubated with luciferin-4A (A), 7ethoxyresorufin (B), $S$-warfarin (C), $S$-mephenytoin (D), dextromethorphan (E), or diltiazem (F) in the presence of various amounts of epalrestat. Each point is the mean of duplicate determinations.

E
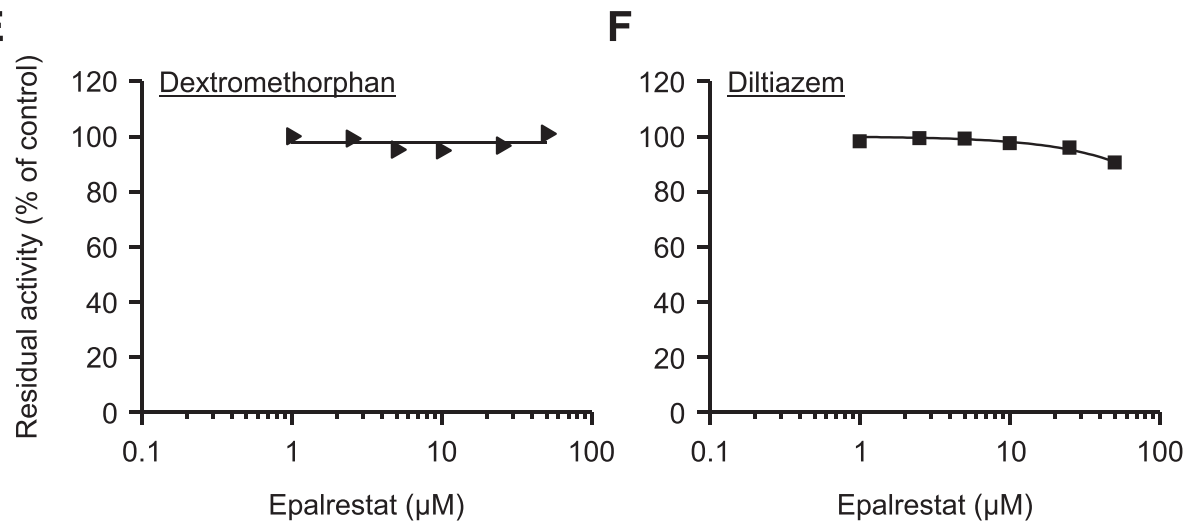

study, we focused on epalrestat, which is an aldose reductase inhibitor used clinically for the treatment of diabetic neuropathy exclusively in Japan (Ramirez and Borja, 2008). Epalrestat predominantly undergoes hydroxylation of its benzene ring in the human liver, which was suggested to be mainly catalyzed by CYP4A11 (Interview Form "KINEDAC Tablets $50 \mathrm{mg}$ " sixth edition, 2013). These findings prompted us to investigate the inhibitory effect of epalrestat on CYP4A11 activity. As expected, epalrestat showed the most potent inhibitory effect against the activity of CYP4A11 among the recombinant CYP enzymes tested. This drug also selectively and effectively inhibited the CYP4A11 activity of HLMs and HRMs. However, epalrestat did not show metabolismdependent inhibition of CYP4A11. These results suggest that epalrestat itself may inhibit CYP4A11 activity.

Our study indicated that the epalrestat-mediated inhibition was highly selective for CYP4A11 because the drug moderately decreased the catalytic activities of CYP2C8, CYP2C9, CYP4F2, CYP4F3B, and CYP4F12. Interestingly, these enzymes as well as CYP4A11 are capable of metabolizing lauric acid and/or arachidonic acid to various extents. CYP2C8 and CYP2C9 are responsible for $\omega /(\omega-1)$-hydroxylation of these fatty acids, although these enzymes are thought to play minor roles in these oxidations (Rifkind et al., 1995; Choi et al., 2018). These enzymes are also representative CYP-derived epoxygenases to produce epoxyeicosatrienoic acids from arachidonic acid (Daikh et al., 1994). CYP4F2, CYP4F3B, and CYP4F12 are CYP-derived $\omega$-hydroxylases of lauric acid and/or arachidonic acid (Powell et al., 1998; Lasker et al., 2000; Hashizume et al., 2001; Fer et al., 2008; Choi et al.,

\section{TABLE 5}

Kinetic parameters for epalrestat-mediated inhibition of luciferin-4A $O$-demethylation catalyzed by HLMs, HRMs, and recombinant CYP4A11 $K_{\mathrm{i}}$ (micromolars) and $\alpha$ values are means \pm S.E. of kinetic parameters.

\begin{tabular}{lccc}
\hline Enzymes & $K_{\mathrm{i}}$ & $\alpha$ & Mode of Inhibition \\
\hline HLMs & $0.349 \pm 0.162$ & $5.26 \pm 6.32$ & Mixed \\
HRMs & $0.198 \pm 0.057$ & $11.0 \pm 8.4$ & Mixed \\
CYP4A11 & $0.824 \pm 0.254$ & $4.33 \pm 2.52$ & Mixed \\
\hline
\end{tabular}






Fig. 9. Effects of preincubation on inhibition of CYP4A11 activity by epalrestat. Recombinant CYP4A11 was preincubated with epalrestat in the presence of NADPH for 0 (closed symbols) or 20 (open symbols) minutes. Incubations were conducted after the addition of luciferin-4A. Each point is the mean of duplicate determinations.

2018). Regardless of these catalytic similarities with CYP4A11, however, CYP2C8, CYP2C9, CYP4F2, CYP4F3B, and CYP4F12 showed low sensitivity to epalrestat-mediated inhibition.

Next, we focused on the selectivity of CYP4A11 inhibition by known CYP4 inhibitors and epalrestat. The present study revealed that the inhibitory effect of HET0016 on CYP4A11 activity was comparable with that on CYP4F2 activity, whereas its inhibitory effect on CYP4A11 was more potent than that of CYP4F3B and much stronger than that of CYP4F12. A previous study showed that HET0016 reduces the arachidonic acid $\omega$-hydroxylase activities of recombinant CYP4A11, CYP4F2, and CYP4F3B to an approximately similar extent (Kehl et al., 2002). These findings partly supported our results. In this study, the inhibitory effect of 17-ODYA failed to discriminate among CYP4A11, CYP4F2, CYP4F3B, and CYP4F12. However, it has been reported that 17-ODYA inhibits CYP4F2 activity more potently than CYP4A11 and CYP4F3B activities (Lasker et al., 2000; Wang et al., 2006). The inhibitory effect of 17-ODYA on CYP4A11 activity in this study was similar to those reported previously (Lasker et al., 2000) and determined by the manufacturer (https://www.promega.jp/resources/pubhub/ enotes/selective-cytochrome-p450-4a11-enzyme-assay-usinga-novel-bioluminescent-probe-substrate/). The inhibitory potency of 17-ODYA against CYP4F3B activity was approximately similar to that reported by the manufacturer (https:// www.promega.jp/resources/pubhub/enotes/cytochrome-p4504f2-and-4f3b-enzyme-assays-using-a-novel-bioluminescentprobe-substrate/). In contrast, the inhibitory effect of 17-ODYA on CYP4F2 activity in the present study was less potent than the previous findings (Lasker et al., 2000; Wang et al., 2006). Taken together, these discrepancies may be explained by the difference in inhibition of CYP4F2 by 17-ODYA. We confirmed that neither HET0016 nor 17-ODYA is a selective inhibitor of CYP4A11. In contrast, epalrestat showed preferential inhibition against CYP4A11 with less than one-tenth of the $\mathrm{IC}_{50}$ values for CYP4F2, CYP4F3B, and CYP4F12. These results indicate that epalrestat is a highly selective inhibitor of CYP4A11 in contrast to these known CYP4 inhibitors.

Epalrestat is the most selective CYP4A11 inhibitor among the chemical inhibitors reported to date, although the potency of epalrestat against CYP4A11 inhibition was much lower than that of HET0016. Moreover, we demonstrated that epalrestat selectively inhibits CYP4A11 activity of HLMs as well as recombinant CYP4A11. Thus, epalrestat will be useful to identify the involvement of CYP4A11 in oxidation of fatty acids and drugs at least under in vitro conditions. As one performs an inhibition study with epalrestat, attention should be paid to experimental conditions. Our study revealed that the inhibitory effect of epalrestat on CYP4A11 activity was decreased by preincubation in the presence of NADPH. This result is most likely due to epalrestat metabolism by CYP4A11, because the drug is also a substrate of CYP4A11. It should be noted that epalrestat is a reversible inhibitor of CYP4A11, unlike 17-ODYA and HET0016, which are irreversible inhibitors (Shak et al., 1985; Seki et al., 2005). Because the utility of epalrestat as an in vivo CYP4A11selective inhibitor remains to be verified, further studies are required. Based on the findings of the present study, epalrestat may be a potential lead compound to develop more highly selective and potent inhibitors for CYP4A11.

In conclusion, we demonstrated that the luciferin-4A $O$ demethylase activity is a good marker activity of CYP4A11 in HLMs and HRMs. Furthermore, our results indicated that epalrestat is a more selective inhibitor of CYP4A11 as compared with known CYP4 inhibitors.

\section{Acknowledgments}

We thank Tanabe Seiyaku (Osaka, Japan) for generously providing $N$-desmethyl diltiazem.

\section{Authorship Contributions}

Participated in research design: Yamaori, Ohmori, Watanabe. Conducted experiments: Yamaori, Araki, Shionoiri, Ikehata, Kamijo.

Performed data analysis: Yamaori, Araki, Shionoiri, Ikehata.

Wrote or contributed to the writing of the manuscript: Yamaori, Ohmori, Watanabe.

\section{References}

Amet Y, Berthou F, Fournier G, Dréano Y, Bardou L, Clèdes J, and Ménez JF (1997) Cytochrome P450 4A and 2E1 expression in human kidney microsomes. Biochem Pharmacol 53:765-771.

Cali JJ, Ma D, Sobol M, Simpson DJ, Frackman S, Good TD, Daily WJ, and Liu D (2006) Luminogenic cytochrome P450 assays. Expert Opin Drug Metab Toxicol 2: 629-645

Chaurasia CS, Alterman MA, Lu P, and Hanzlik RP (1995) Biochemical characterization of lauric acid $\omega$-hydroxylation by a CYP4A1/NADPH-cytochrome P450 reductase fusion protein. Arch Biochem Biophys 317:161-169.

Choi S, Han S, Lee H, Chun YJ, and Kim D (2013) Evaluation of luminescent P450 analysis for directed evolution of human CYP4A11. Biomol Ther (Seoul) 21 487-492.

Choi YJ, Zhou Y, Lee JY, Ryu CS, Kim YH, Lee K, and Kim SK (2018) Cytochrome P450 4A11 inhibition assays based on characterization of lauric acid metabolites. Food Chem Toxicol 112:205-215.

Clarke SE, Baldwin SJ, Bloomer JC, Ayrton AD, Sozio RS, and Chenery RJ (1994) Lauric acid as a model substrate for the simultaneous determination of cytochrome P450 2E1 and 4A in hepatic microsomes. Chem Res Toxicol 7:836-842.

Crespi CL, Chang TK, and Waxman DJ (2006) Determination of CYP4A11-catalyzed lauric acid 12-hydroxylation by high-performance liquid chromatography with radiometric detection. Methods Mol Biol 320:143-147.

Daikh BE, Lasker JM, Raucy JL, and Koop DR (1994) Regio- and stereoselective epoxidation of arachidonic acid by human cytochromes P450 2C8 and 2C9. $J$ Pharmacol Exp Ther 271:1427-1433.

Dirven HA, de Bruijn AA, Sessink PJ, and Jongeneelen FJ (1991) Determination of the cytochrome P-450 IV marker, $\omega$-hydroxylauric acid, by high-performance liquid chromatography and fluorimetric detection. J Chromatogr A 564:266-271.

Edson KZ and Rettie AE (2013) CYP4 enzymes as potential drug targets: focus on enzyme multiplicity, inducers and inhibitors, and therapeutic modulation of 20 -hydroxyeicosatetraenoic acid (20-HETE) synthase and fatty acid $\omega$-hydroxylase activities. Curr Top Med Chem 13:1429-1440.

Fer M, Corcos L, Dréano Y, Plée-Gautier E, Salaün JP, Berthou F, and Amet Y (2008) Cytochromes P450 from family 4 are the main omega hydroxylating enzymes in humans: CYP4F3B is the prominent player in PUFA metabolism. J Lipid Res 49: 2379-2389.

Gainer JV, Bellamine A, Dawson EP, Womble KE, Grant SW, Wang Y, Cupples LA, Guo CY, Demissie S, O'Donnell CJ, et al. (2005) Functional variant of CYP4A11 
20-hydroxyeicosatetraenoic acid synthase is associated with essential hypertension. Circulation 111:63-69.

Hanioka N, Yamamoto M, Iwabu H, Jinno H, Tanaka-Kagawa T, Naito S, Shimizu T, Masuda K, Katsu T, and Narimatsu S (2007) Functional characterization of human and cynomolgus monkey cytochrome P450 2E1 enzymes. Life Sci 81:1436-1445.

Hashizume T, Imaoka S, Hiroi T, Terauchi Y, Fujii T, Miyazaki H, Kamataki T, and Funae Y (2001) cDNA cloning and expression of a novel cytochrome p450 (cyp4f12) from human small intestine. Biochem Biophys Res Commun 280: $1135-1141$.

Hermann M, Hellermann JP, Quitzau K, Hoffmann MM, Gasser T, Meinertz T, Münzel T, Fleming I, and Lüscher TF (2009) CYP4A11 polymorphism correlates with coronary endothelial dysfunction in patients with coronary artery disease-the ENCORE Trials. Atherosclerosis 207:476-479.

Hoch U, Zhang Z, Kroetz DL, and Ortiz de Montellano PR (2000) Structural determination of the substrate specificities and regioselectivities of the rat and human fatty acid $\omega$-hydroxylases. Arch Biochem Biophys 373:63-71.

Jarrar YB, Cho SA, Oh KS, Kim DH, Shin JG, and Lee SJ (2013) Identification of cytochrome P450s involved in the metabolism of arachidonic acid in human platelets. Prostaglandins Leukot Essent Fatty Acids 89:227-234.

Jiang R, Yamaori S, Okamoto Y, Yamamoto I, and Watanabe K (2013) Cannabidiol is a potent inhibitor of the catalytic activity of cytochrome P450 2C19. Drug Metab Pharmacokinet 28:332-338.

Kamdem LK, Flockhart DA, and Desta Z (2011) In vitro cytochrome P450-mediated metabolism of exemestane. Drug Metab Dispos 39:98-105.

Kehl F, Cambj-Sapunar L, Maier KG, Miyata N, Kametani S, Okamoto H, Hudetz AG, Schulte ML, Zagorac D, Harder DR, et al. (2002) 20-HETE contributes to the acute fall in cerebral blood flow after subarachnoid hemorrhage in the rat. Am J Physiol Heart Circ Physiol 282:H1556-H1565.

Lasker JM, Chen WB, Wolf I, Bloswick BP, Wilson PD, and Powell PK (2000) Formation of 20-hydroxyeicosatetraenoic acid, a vasoactive and natriuretic eicosanoid, in human kidney: role of Cyp4F2 and Cyp4A11. J Biol Chem 275:4118-4126.

Miyata N, Taniguchi K, Seki T, Ishimoto T, Sato-Watanabe M, Yasuda Y, Doi M, Kametani S, Tomishima Y, Ueki T, et al. (2001) HET0016, a potent and selective inhibitor of 20-HETE synthesizing enzyme. Br J Pharmacol 133:325-329.

Muerhoff AS, Williams DE, Reich NO, CaJacob CA, Ortiz de Montellano PR, and Masters BS (1989) Prostaglandin and fatty acid omega- and (omega-1) oxidation in rabbit lung: acetylenic fatty acid mechanism-based inactivators as specific inhibitors. J Biol Chem 264:749-756.

Mukoyoshi M, Nishimura S, Hoshide S, Umeda S, Kanou M, Taniguchi K and Muroga $\mathrm{H}$ (2008) In vitro drug-drug interaction studies with febuxostat, a novel non-purine selective inhibitor of xanthine oxidase: plasma protein binding, identification of metabolic enzymes and cytochrome P450 inhibition. Xenobiotica 38:496-510.

Nelson DR, Koymans L, Kamataki T, Stegeman JJ, Feyereisen R, Waxman DJ, Waterman MR, Gotoh O, Coon MJ, Estabrook RW, et al. (1996) P450 superfamily: update on new sequences, gene mapping, accession numbers and nomenclature. Pharmacogenetics 6:1-42.

Powell PK, Wolf I, Jin R, and Lasker JM (1998) Metabolism of arachidonic acid to 20-hydroxy-5,8,11,14-eicosatetraenoic acid by P450 enzymes in human liver: involvement of CYP4F2 and CYP4A11. J Pharmacol Exp Ther 285:1327-1336.

Powell PK, Wolf I, and Lasker JM (1996) Identification of CYP4A11 as the major lauric acid $\omega$-hydroxylase in human liver microsomes. Arch Biochem Biophys 335: 219-226.

Ramirez MA and Borja NL (2008) Epalrestat: an aldose reductase inhibitor for the treatment of diabetic neuropathy. Pharmacotherapy 28:646-655.
Rifkind AB, Lee C, Chang TK, and Waxman DJ (1995) Arachidonic acid metabolism by human cytochrome $\mathrm{P} 450 \mathrm{~s} 2 \mathrm{C} 8,2 \mathrm{C} 9,2 \mathrm{E} 1$, and 1A2: regioselective oxygenation and evidence for a role for CYP2C enzymes in arachidonic acid epoxygenation in human liver microsomes. Arch Biochem Biophys 320:380-389.

Saito T, Honda M, Takahashi M, Tsukada C, Ito M, Katono Y, Hosono H, Saigusa D, Suzuki N, Tomioka Y, et al. (2015) Functional characterization of 10 CYP4A11 allelic variants to evaluate the effect of genotype on arachidonic acid w-hydroxylation. Drug Metab Pharmacokinet 30:119-122.

Seki T, Wang M-H, Miyata N, and Laniado-Schwartzman M (2005) Cytochrome P450 4A isoform inhibitory profile of N-hydroxy-N'-(4-butyl-2-methylphenyl)-formamidine (HET0016), a selective inhibitor of 20-HETE synthesis. Biol Pharm Bull 28:1651-1654.

Shak S, Reich NO, Goldstein IM, and Ortiz de Montellano PR (1985) Leukotriene B $\omega$-hydroxylase in human polymorphonuclear leukocytes: suicidal inactivation by acetylenic fatty acids. J Biol Chem 260:13023-13028.

Sugimoto K, Akasaka H, Katsuya T, Node K, Fujisawa T, Shimaoka I, Yasuda O, Ohishi M, Ogihara T, Shimamoto K, et al. (2008) A polymorphism regulates CYP4A11 transcriptional activity and is associated with hypertension in a Japanese population. Hypertension 52:1142-1148.

Wang MZ, Saulter JY, Usuki E, Cheung YL, Hall M, Bridges AS, Loewen G, Parkinson OT, Stephens CE, Allen JL, et al. (2006) CYP4F enzymes are the major enzymes in human liver microsomes that catalyze the $O$-demethylation of the antiparasitic prodrug DB289 [2,5-bis(4-amidinophenyl)furan-bis-O-methylamidoxime]. Drug Metab Dispos 34:1985-1994.

Wu CC, Gupta T, Garcia V, Ding Y, and Schwartzman ML (2014) 20-HETE and blood pressure regulation: clinical implications. Cardiol Rev 22:1-12.

Yamane M, Kawashima K, Yamaguchi K, Nagao S, Sato M, Suzuki M, Honda K, Hagita H, Kuhlmann O, Poirier A, et al. (2015) In vitro profiling of the metabolism and drug-drug interaction of tofogliflozin, a potent and highly specific sodiumglucose co-transporter 2 inhibitor, using human liver microsomes, human hepatocytes, and recombinant human CYP. Xenobiotica 45:230-238.

Yamaori S, Ebisawa J, Okushima Y, Yamamoto I, and Watanabe K (2011a) Potent inhibition of human cytochrome P450 3A isoforms by cannabidiol: role of phenolic hydroxyl groups in the resorcinol moiety. Life Sci 88:730-736.

Yamaori S, Koeda K, Kushihara M, Hada Y, Yamamoto I, and Watanabe K (2012) Comparison in the in vitro inhibitory effects of major phytocannabinoids and polycyclic aromatic hydrocarbons contained in marijuana smoke on cytochrome P450 2C9 activity. Drug Metab Pharmacokinet 27:294-300.

Yamaori S, Kushihara M, Yamamoto I, and Watanabe K (2010) Characterization of major phytocannabinoids, cannabidiol and cannabinol, as isoform-selective and potent inhibitors of human CYP1 enzymes. Biochem Pharmacol 79:1691-1698.

Yamaori S, Maeda C, Yamamoto I, and Watanabe K (2011b) Differential inhibition of human cytochrome P450 2A6 and 2B6 by major phytocannabinoids. Forensic Toxicol 29:117-124

Yamaori S, Okamoto Y, Yamamoto I, and Watanabe K (2011c) Cannabidiol, a major phytocannabinoid, as a potent atypical inhibitor for CYP2D6. Drug Metab Dispos 39:2049-2056.

Zou AP, Ma YH, Sui ZH, Ortiz de Montellano PR, Clark JE, Masters BS, and Roman RJ (1994) Effects of 17-octadecynoic acid, a suicide-substrate inhibitor of cytochrome P450 fatty acid $\omega$-hydroxylase, on renal function in rats. J Pharmacol Exp Ther 268:474-481.

Address correspondence to: Dr. Satoshi Yamaori, Department of Pharmacy, Shinshu University Hospital, 3-1-1 Asahi, Matsumoto 390-8621, Japan. E-mail: syamaori@shinshu-u.ac.jp 